\title{
Physiological levels of nitrate support anoxic growth by denitrification of Pseudomonas aeruginosa at growth rates reported in cystic fibrosis lungs and sputum
}

\section{Laura Line ${ }^{1,2}$, Morten Alhede ${ }^{1,2}$, Mette Kolpen ${ }^{1,2}$, Michael Küh/ ${ }^{3,4,5}$, Oana Ciofu' ${ }^{2}$, Thomas Bjarnsholt ${ }^{1,2}$, Claus Moser ${ }^{1}$, Masanori Toyofuku ${ }^{6}$, Nobuhiko Nomura ${ }^{6}$, Niels Høiby ${ }^{1,2}$ and Peter Ø. Jensen ${ }^{1 *}$}

${ }^{1}$ Department of Clinical Microbiology, Rigshospitalet, Copenhagen, Denmark

${ }^{2}$ Department of International Health, Immunology and Microbiology, Faculty of Health Sciences, University of Copenhagen, Copenhagen, Denmark

${ }^{3}$ Marine Biological Section, Department of Biology, University of Copenhagen, Copenhagen, Denmark

${ }^{4}$ Plant Functional Biology and Climate Change Cluster, University of Technology Sydney, Sydney, NSW, Australia

${ }^{5}$ Singapore Centre on Environmental Life Sciences Engineering, Nanyang Technological University, Singapore, Singapore

${ }^{6}$ Graduate School of Life and Environmental Sciences, University of Tsukuba, Tsukuba, Japan

\section{Edited by:}

Evangelos Giamarellos-Bourboulis, University of Athens, Medical

School, Greece

Reviewed by:

Frederic Lamoth, Duke University, USA

George Dimopoulos, University Hospital ATTIKON, Greece

\section{*Correspondence:}

Peter $\varnothing$. Jensen, Department of Clinical Microbiology, Rigshospitalet,

Juliane Mariesvej 22, 2100

Copenhagen, Denmark

e-mail: peter.oestrup.jensen@

regionh.dk
Chronic Pseudomonas aeruginosa lung infection is the most severe complication in patients with cystic fibrosis (CF). The infection is characterized by the formation of biofilm surrounded by numerous polymorphonuclear leukocytes (PMNs) and strong $\mathrm{O}_{2}$ depletion in the endobronchial mucus. We have reported that $\mathrm{O}_{2}$ is mainly consumed by the activated PMNs, while $\mathrm{O}_{2}$ consumption by aerobic respiration is diminutive and nitrous oxide $\left(\mathrm{N}_{2} \mathrm{O}\right)$ is produced in infected CF sputum. This suggests that the reported growth rates of $P$. aeruginosa in lungs and sputum may result from anaerobic respiration using denitrification. The growth rate of $P$. aeruginosa achieved by denitrification at physiological levels $(\sim 400 \mu \mathrm{M})$ of nitrate $\left(\mathrm{NO}_{3}^{-}\right)$is however, not known. Therefore, we have measured growth rates of anoxic cultures of PAO1 and clinical isolates $(n=12)$ in LB media supplemented with $\mathrm{NO}_{3}^{-}$and found a significant increase of growth when supplementing PAO1 and clinical isolates with $\geq 150 \mu \mathrm{M} \mathrm{NO}_{3}^{-}$and $100 \mu \mathrm{M} \mathrm{NO}_{3}^{-}$, respectively. An essential contribution to growth by denitrification was demonstrated by the inability to establish a significantly increased growth rate by a denitrification deficient $\Delta$ nirS-N mutant at $<1 \mathrm{mM}$ of $\mathrm{NO}_{3}^{-}$. Activation of denitrification could be achieved by supplementation with as little as $62.5 \mu \mathrm{M}$ of $\mathrm{NO}_{3}^{-}$according to the significant production of $\mathrm{N}_{2} \mathrm{O}$ by the nitrous oxide reductase deficient $\Delta$ nos $Z$ mutant. Studies of the promoter activity, gene transcripts, and enzyme activity of the four N-oxide reductases in PAO1 (Nar, Nir, Nor, Nos) further verified the engagement of denitrification, showing a transient increase in activation and expression and rapid consumption of $\mathrm{NO}_{3}^{-}$followed by a transient increase of $\mathrm{NO}_{2}^{-}$. Growth rates obtained by denitrification in this study were comparable to our reported growth rates in the majority of $P$. aeruginosa cells in CF lungs and sputum. Thus, we have demonstrated that denitrification is required for $P$. aeruginosa growth in infected endobronchial CF mucus.

Keywords: Pseudomonas aeruginosa, denitrification, growth, cystic fibrosis

\section{INTRODUCTION}

Chronic lung infection by Pseudomonas aeruginosa is the most severe complication in cystic fibrosis (CF) patients (Koch and Høiby, 2000). The infection is characterized by biofilm aggregates of $P$. aeruginos $a$ within the endobronchial mucus surrounded by high densities of active polymorphonuclear leukocytes (PMNs) (Bjarnsholt et al., 2009). The activity of PMNs has been shown to be the major cause of $\mathrm{O}_{2}$ depletion due to production of the reactive oxygen species superoxide $\left(\mathrm{O}_{2}^{-}\right)$and nitric oxide $(\mathrm{NO})$ within sputum samples (Kolpen et al., 2010, 2014a). Combined with the $\mathrm{O}_{2}$ consumption by lung epithelial cells, micro-oxic to anoxic conditions can develop in the airways of CF patients (Worlitzsch et al., 2002), which have been further evidenced by the upregulation of the $\mathrm{O}_{2}$ sensing anaerobic global regulator (Anr) in P. aeruginosa isolates (Hoboth et al., 2009) and the presence of obligate anaerobes such as Prevotella within sputum (Tunney et al., 2008). While $\mathrm{O}_{2}$ depletion by microbial aerobic respiration is thus diminutive, $P$. aeruginosa has been shown to be actively growing within the mucus of lungs (Kragh et al., 2014) and sputum (Yang et al., 2008). As a facultative anaerobe, this growth may be attributable to $P$. aeruginosa's ability to perform anaerobic respiration by denitrification.

Denitrification was first described as the liberation of gaseous nitrogen oxides ( $\mathrm{N}$-oxides) by bacteria (Gayon and Dupetit, 1886) and involves the utilization of $\mathrm{N}$-oxides as alternative electron acceptors for respiration (Figure 1). This definition of 
denitrification means that while nitrate $\left(\mathrm{NO}_{3}^{-}\right)$reduction to nitrite $\left(\mathrm{NO}_{2}^{-}\right)$contributes directly to energy generation via the proton pumping action of the membrane-bound nitrate reductase (NarGHIJ) (Chen and Strous, 2013), the first step in strict denitrification is actually $\mathrm{NO}_{2}^{-}$reduction, where $\mathrm{NO}$ is the first gaseous product arising from $\mathrm{NO}_{3}^{-}$reduction (Zumft, 2005).

Engagement of denitrification in infected CF lungs is in accordance with the production of the denitrification intermediate nitrous oxide $\left(\mathrm{N}_{2} \mathrm{O}\right)$ in sputum (Kolpen et al., 2014b),

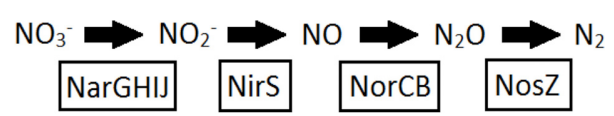

FIGURE 1 | Denitrification pathway. Reduction of nitrate to nitrite, nitric oxide, nitrous oxide, and finally dinitrogen. The four reductase enzymes nitrate reductase, nitrite reductase, nitric oxide reductase, and nitrous oxide reduction are boxed below. Nitrite reduction marks the first step of strict denitrification. the presence of the denitrification marker OprF and antibodies against OprF in lung secretions and sera (Yoon et al., 2002), antibodies against Nar in sera (Beckmann et al., 2005) and the upregulation of the denitrification reductases in CF isolates (Son et al., 2007; Hoboth et al., 2009; Lee et al., 2011). Additionally, after antimicrobial treatment the infected sputum content of $\mathrm{NO}_{3}^{-}$increases (Grasemann et al., 1998) indicating a reduction in the activity of denitrifying cells.

\section{MATERIALS AND METHODS BACTERIAL STRAINS AND PLASMIDS}

The strains and plasmids used in this study are listed in Table 1. Primers used in this study are listed in Table 2. The wild type strain used for experiments and reporter plasmid insertion was PAO1 obtained from the Pseudomonas Genetic Stock Center (www.pseudomonas.med.ecu.edu, strain PAO0001). The Holloway PAO1 wild type was used as the control for the examinations of the Holloway PAO1 $\Delta$ nirS- $N$ and the Holloway PAO1 $\Delta$ nos $Z$ mutants. The PAO1 strains grew at similar rates under anoxic conditions.

Table 1 | $P$. aeruginosa strains used for this study.

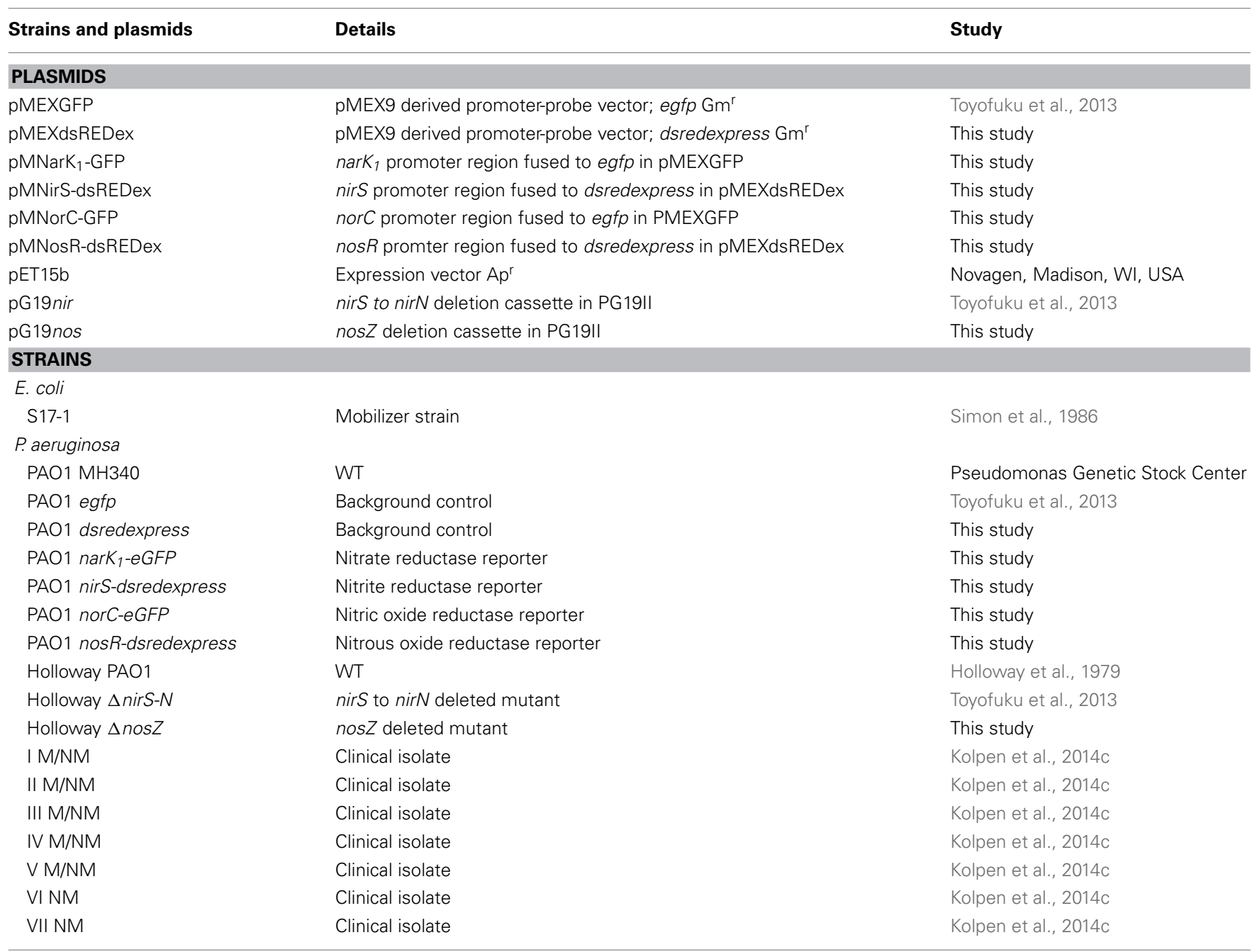

$\mathrm{Gm}^{r}$ (Gentamicin resistant), Ap $\mathrm{p}^{r}$ (Ampicillin resistant), Mucoid (M), Non-mucoid (NM), Wild type (WT). 
Table 2 | Primer sequences used in this study.

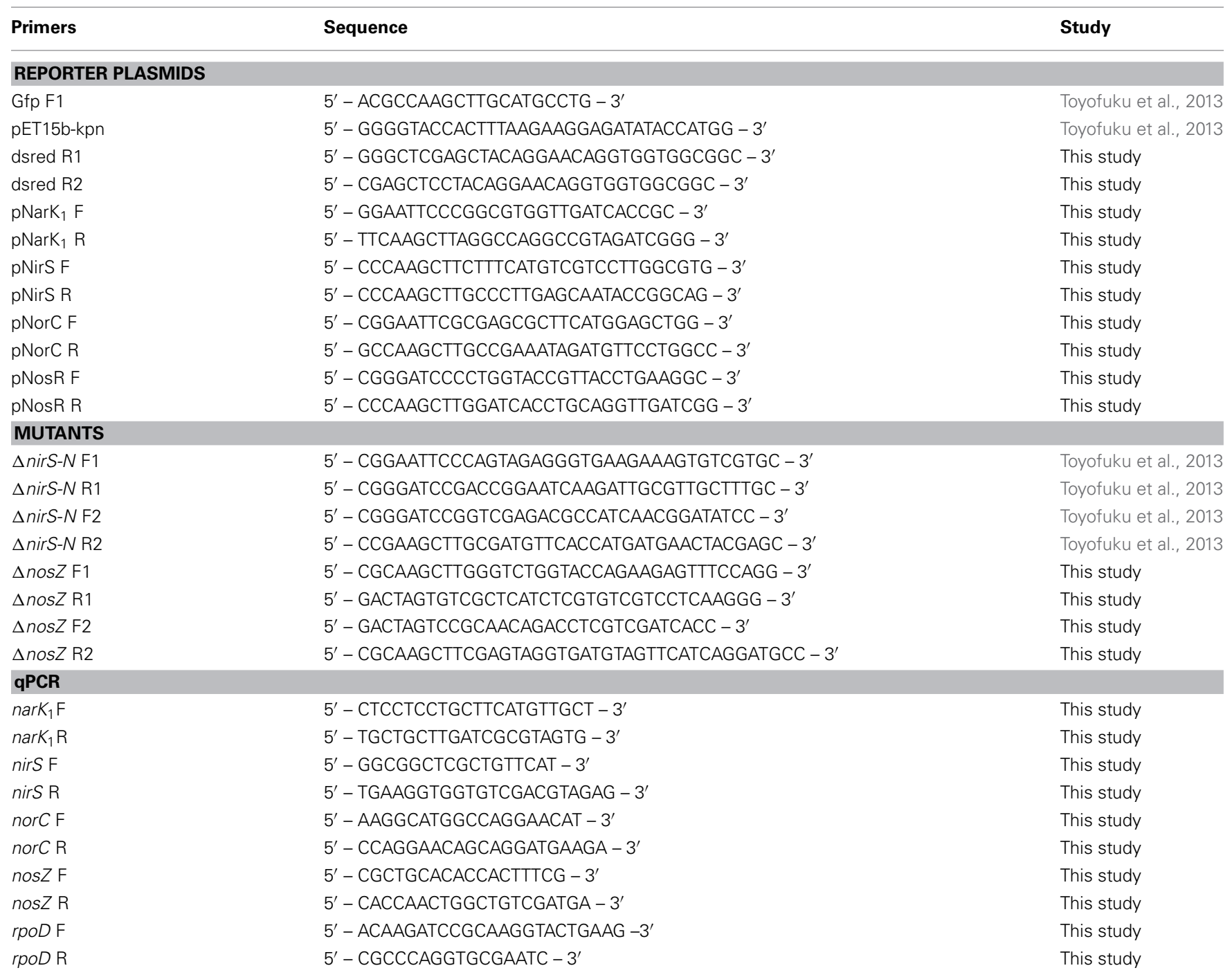

Forward (F), Reverse (R).

Plasmids containing eGFP or DsRed-Express tagged reporter genes were derived from pME as pG19nir and pG19nos plasmids carrying deletion cassettes of nirS to $\operatorname{nir} N$ and nos $Z$ were constructed with the same procedure described previously (Maseda et al., 2004). The pG19II-derived plasmids were transferred into Holloway PAO1 by conjugating with E. coli S17-1 (Simon et al., 1986) followed by homologous recombination described elsewhere (Maseda et al., 2004). The mutants were analyzed by polymerase chain reaction (PCR) (Toyofuku et al., 2013).

The eGFP-based promoter probe plasmid, pMEXGFP, was constructed as described previously (Toyofuku et al., 2013). The promoter regions of $n a r K_{1}$ and $n o r C$ were amplified with $\mathrm{pNarK}_{1}$ $\mathrm{F} / \mathrm{pNarK}_{1} \mathrm{R}$ or $\mathrm{pNorC} \mathrm{F} / \mathrm{pNorC} \mathrm{R}$ primer pairs and cloned into pMEXeGFP for promoter activity assays. pMEXdsREDex was constructed in the same way, with dsredexpress amplified using the primer pairs Gfp F1/dsred R1 (Table 2) and post subcloning, the primer pair pET15b-kpn/dsred R2 (Table 2) was used to amplify a RBS-fused DsRed-Express to clone into the pMEX9 plasmid (Toyofuku et al., 2007). The promoter regions of nirS and nosR were amplified with the primer pairs $\mathrm{pNirS} F / \mathrm{pNirS} \mathrm{R}$ or pNosR F/pNosR R (Table 2) and cloned into the pMEdsREDex for promoter activity assays.

The reporter plasmid insertion was achieved by preparation of electro-competent cells as previously described (Choi et al., 2005 ) and subsequent electroporation at $25 \mu \mathrm{F}, 200 \Omega, 2.5 \mathrm{kV}$ with $1 \mu \mathrm{l}$ of plasmid DNA for $100 \mu \mathrm{l}$ of electro-competent cells. Transformed cells were selected for by plating with $30 \mathrm{ng} \mathrm{ml}^{-1}$ gentamicin (Sigma-Aldrich, St. Louis, MO, USA) and frozen cultures were produced from a single colony.

Clinical strains (5 mucoid and 7 non-mucoid) were isolated from expectorated sputum of 7 chronically infected CF patients (Kolpen et al., 2014b).

\section{ANOXIC GROWTH EXPERIMENTS}

In this study, we first establish experimental evidence for the ability of physiological levels of $\mathrm{NO}_{3}^{-}$to support anoxic growth of 
P. aeruginosa PAO1 wild type and 12 clinical isolates at rates comparable to those in CF lungs and sputum. To discern that a significant portion of the attained growth was attributable to denitrification, a strain incapable of denitrification due to a mutation in the nitrite reductase (Nir) operon was studied.

All experiments requiring anoxic conditions were performed in an anoxic bench (Concept 400, Thermo Scientific, Waltham, $\mathrm{MA}$, USA) with $\mathrm{O}_{2}<0.02 \%$ routinely monitored with an luminescent dissolved oxygen $\mathrm{O}_{2}$ sensor (HQ40d multi, $\mathrm{HACH}$ Company, Loveland, CO, US). Media was sealed with parafilm (Bemis, Neenah, WI, USA) and allowed to equilibrate for a minimum of 3 days. Strains were plated from frozen cultures and single colonies were used to initiate normoxic overnight cultures. They were then adjusted to $\mathrm{OD}_{600} 0.1$ and regrown to $\mathrm{OD}_{600} 0.4$ to ensure all cells were in the exponential growth phase. The culture was inoculated by diluting 1:100 in relevant anoxic Luria-Bertani broth (LB) media supplemented with $\mathrm{KNO}_{3}$ (Sigma-Aldrich) to obtain the noted concentrations of $\mathrm{NO}_{3}^{-}$in $2 \mathrm{ml}$ glass vials (Schuett Biotec, Göttingen, DE), which were sealed inside the anoxic bench before transfer to shaking at $200 \mathrm{rpm}$. Physiological levels of $\mathrm{NO}_{3}^{-}$here are considered to be approximately $400 \mu \mathrm{M}$ with a maximum of $1 \mathrm{mM}$ based on the concentrations of $\mathrm{NO}_{3}^{-}$detected in CF sputum (Grasemann et al., 1998; Palmer et al., 2007; Kolpen et al., 2014a). Vials were shown to remain anoxic for a minimum of 2 days using anaerobic indicator strips (SSI Diagnostica, Hillerød, Denmark) that changed from white to blue in the presence of oxygen. Optical density was measured directly in the vials at $600 \mathrm{~nm}\left(\mathrm{OD}_{600}\right)$ by a spectrophotometer (Shimadzu, Kyoto, JP) and values obtained were shown to correlate linearly to dilutions of an overnight culture in $\mathrm{LB}$ at $\mathrm{OD}_{600}$ values $>0.02$. Accordingly, only $\mathrm{OD}$ values higher than 0.02 were used in growth rate calculations. Growth rates were calculated as described (Widdel, 2007).

The suitability of the assay was demonstrated in cultures of PAO1 supplemented with $100 \mathrm{mM} \mathrm{NO}_{3}^{-}$, where our measured growth rate of 0.7 divisions $\mathrm{h}^{-1}$ and final $\mathrm{OD}_{600}$ of 1.0 (data not shown) corresponded well with previously reported growth rates of $P$. aeruginosa (Alvarez-Ortega and Harwood, 2007; Lee et al., 2012; Fang et al., 2013).

\section{PROMOTER ACTIVITY-REPORTER STRAINS}

To further confirm the engagement of denitrification, the transcripts and promoter activity of the four $\mathrm{N}$-oxide reductases (Nar, Nir, Nor, Nos) were studied using qRT-PCR and fluorescent reporter strains, respectively. Reporter strains with the promoter region of the four denitrification reductase operons; narK $K_{1} K_{2} G H I J$, nirSMCFDLGHJEN, norCBD, nosRZDFYL (Schobert and Jahn, 2010) fused to fluorescent tags of either eGFP or DsRed-Express (Table 1) were used to study promoter activation under anoxic conditions with $400 \mu \mathrm{M} \mathrm{KNO}_{3}$ supplemented LB as described above.

GFP and DsRed require $\mathrm{O}_{2}$ for chromophore maturation (Craggs, 2009; Strack et al., 2010). Consequently, $1600 \mathrm{ng} \mathrm{ml}^{-1}$ chloramphenicol (Sigma-Aldrich) was added to the cultures to prevent new protein synthesis (Toyofuku et al., 2013) with shaking for $1 \mathrm{~h}$ at $37^{\circ} \mathrm{C}$ in atmospheric air prior to measurement to allow the chromophore to develop-termed oxic fluorescence recovery (OFR) (Zhang et al., 2005). The signal was detected by flow cytometry as described below. The fluorescence values obtained were corrected for background fluorescence seen in the control strains with eGFP and dsredexpress unconjugated to a promoter.

\section{FLOW CYTOMETRY}

Detection of reporter strain fluorescence was performed using a FACSCanto flowcytometer (BD Biosciences, San Jose, CA, USA) with a $488 \mathrm{~nm}$ argon laser. eGFP was detected in FL-1 with a $502 \mathrm{~nm}$ long pass filter and a 530/30 nm band pass emission filter. DsRed-Express fluorescence was collected in FL-2 with a $556 \mathrm{~nm}$ long pass filter and 585/42 $\mathrm{nm}$ band pass emission filter. To maximize resolution, samples were analyzed at low flow rate corresponding to $10 \mu \mathrm{l} \mathrm{min}{ }^{-1}$. At least 10,000 events were recorded for each sample. Cytometer Setup and Tracking Beads (BD Biosciences) were used for instrument calibration, and flow data were processed and analyzed by Diva (BD Biosciences).

\section{DENITRIFICATION GENE TRANSCRIPT EXPRESSION—RNA EXTRACTION AND REVERSE TRANSCRIPTION}

PAO1 was grown in triplicate for $3 \mathrm{~h}$ under anoxia with either unsupplemented $\mathrm{LB}$ or $\mathrm{LB}$ with $400 \mu \mathrm{M} \mathrm{KNO}_{3}$. The $3 \mathrm{~h}$ time point was chosen as it represented the approximate peak of promoter activity, as seen in the reporter strains. After $3 \mathrm{~h}$, the cultures were mixed with 2 volumes of RNAlater (Ambion, Austin, TX, USA) within the anoxic bench for transcript stabilization and kept at $4^{\circ} \mathrm{C}$ overnight before freezing at $-80^{\circ} \mathrm{C}$. The cultures were subsequently thawed on ice, centrifuged to harvest the cells and lysed with $100 \mu \mathrm{l}$ of $1 \mathrm{mg} \mathrm{m}^{-1}$ lysozyme (Affymetrix, Cleveland, OH, USA) at room temperature for $13 \mathrm{~min}$. Total RNA was extracted with RNeasy Mini Kits (Qiagen Danmark, Limburg, NL) and contaminating chromosomal DNA was removed by treatment with RQ1 RNase-free DNase (Promega, Madison, WI, USA). RNA quality was detected in a NanoDrop spectrophotometer (Thermo Scientific). cDNA was synthesized from 250 to $500 \mathrm{ng}$ of RNA (depending on the concentration extracted) and High Capacity RNA-to-cDNA Master Mix (Applied Biosystems, Foster City, CA, US) with a final reaction volume of $20 \mu \mathrm{l}$ in a 2720 Thermal Cycler (Applied Biosystems). The conditions consisted of $5 \mathrm{~min}$ at $25^{\circ} \mathrm{C}, 30 \mathrm{~min}$ at $42^{\circ} \mathrm{C}, 5 \mathrm{~min}$ at $85^{\circ} \mathrm{C}$ and subsequent holding at $4^{\circ} \mathrm{C}$. cDNA was frozen at $-20^{\circ} \mathrm{C}$. Negative controls contained template with the Master Mix replaced with water. cDNA was diluted 1:100 for qPCR.

\section{PRIMER DESIGN}

Primers for the denitrification genes narK $K_{1}$, nirS, nor C, nosR and the reference gene $r p o D$ were designed using Integrated DNA Technologies Primer Quest software (http://www.idtdna.com) using sequences from the PAO1 Genome Sequence, Pseudomonas Genome Database (Winsor et al., 2011) (Table 2).

\section{QUANTITATIVE PCR}

Each PCR mix had a final volume of $20 \mu$ l containing $10 \mu \mathrm{l}$ SYBR Green qPCR Master Mix 2x (Applied Biosystems) $2 \mu \mathrm{l}$ cDNA, $2 \mu \mathrm{l}$ of 2 pmol $\mu \mathrm{l}^{-1}$ forward and reverse primers and $4 \mu \mathrm{l}$ water. Quantitative real-time PCR was performed with a StepOnePlus, 
Real-Time PCR system (Applied Biosystems) with initial denaturation at $95^{\circ} \mathrm{C}$ for $10 \mathrm{~min}$ followed by 40 cycles of $95^{\circ} \mathrm{C}$ for $15 \mathrm{~s}$, $60^{\circ} \mathrm{C}$ for $30 \mathrm{~s}$ and $72^{\circ} \mathrm{C}$ for $30 \mathrm{~s}$.

Data were normalized to the expression of $r p o D$, a housekeeping gene encoding the primary sigma factor for RNA polymerase found to be constitutively expressed in $P$. aeruginosa (Savli et al., 2003). To control for variations between runs, the housekeeping and target genes for each of the three samples were amplified in one 96-well plate. Expression of the target genes in the cultures with $400 \mu \mathrm{M} \mathrm{KNO} 3$ was compared to the unsupplemented cultures and the difference expressed as $\mathrm{n}$-fold change.

\section{$\mathrm{NO}_{3}^{-}$AND NO $\mathbf{2}_{2}^{-}$QUANTIFICATION}

For measuring $\mathrm{NO}_{3}^{-}$and $\mathrm{NO}_{2}^{-}$concentration in the culture media, the supernatant was harvested and sterile filtrated through a syringe filter (TRP, Trasadingen, SUI) (pore size $0.22 \mu \mathrm{m}$ ) and frozen at $-20^{\circ} \mathrm{C}$ for later measurement. $\mathrm{NO}_{3}^{-}$and $\mathrm{NO}_{2}^{-}$ were detected in 96-well microtiter plates using a modified Griess nitrite/nitrate colorimetric assay (Cayman Chemicals, Ann Arbor, MI, USA) according to manufacturer's instructions and as previously described (Kolpen et al., 2014a). Briefly, $\mathrm{NO}_{2}^{-}$ concentration was estimated by incubating with the Griess Reagent, converting $\mathrm{NO}_{2}^{-}$into a purple azo-compound detected by absorbance at $540 \mathrm{~nm}$ in a Multiskan EX plate reader (Thermo Scientific). For $\mathrm{NO}_{3}^{-}$concentration, $\mathrm{NO}_{3}^{-}$was first converted to $\mathrm{NO}_{2}^{-}$by incubation with $\mathrm{NO}_{3}^{-}$reductase and subsequent addition of the Griess reagent to detect total $\mathrm{NO}_{3}^{-}$plus $\mathrm{NO}_{2}^{-}$. The $\mathrm{NO}_{3}^{-}$concentration was calculated as the difference between the total $\mathrm{NO}_{2}^{-}$and $\mathrm{NO}_{3}^{-}$concentration and the $\mathrm{NO}_{2}^{-}$concentration. The detection limit of the assay was $\sim 2 \mu \mathrm{M}$ for $\mathrm{NO}_{2}^{-}$and $\sim 5 \mu \mathrm{M}$ for $\mathrm{NO}_{3}^{-}$.

\section{MICROSENSOR MEASUREMENTS OF $\mathrm{N}_{\mathbf{2}} \mathbf{O}$}

Additionally, reductase activity was elucidated by measuring consumption of $\mathrm{NO}_{3}^{-}$and production of $\mathrm{NO}_{2}^{-}$as well as measurements of $\mathrm{N}_{2} \mathrm{O}$ gas accumulation in a $\Delta$ nos $Z$ mutant strain incapable of the final reduction step in denitrification of $\mathrm{N}_{2} \mathrm{O}$ to
$\mathrm{N}_{2}$. Each small glass vial (Schuett Biotec, Göttingen, DE) containing anoxic planktonic cultures of either PAO1 WT or the $\Delta n o s Z$ mutant were placed in a $37^{\circ} \mathrm{C}$ heated rack and kept sealed prior to individual measurements, upon which they were shaken and the lid removed. Immediately after, $\mathrm{N}_{2} \mathrm{O}$ was detected in the media using an amperometric $\mathrm{N}_{2} \mathrm{O}$ microsensor (Andersen et al., 2001) with a tip diameter of $25 \mu \mathrm{m}$ (Unisense A/S, Aarhus, DK) as previously described (Kolpen et al., 2014a). Each measurement consisted of a $5 \mathrm{~s}$ wait period followed by $5 \mathrm{~s}$ measurements taken at 7, $1 \mathrm{~mm}$ intervals with data acquisition and sensor positioning controlled by the Sensortrace Pro 2.0 (Unisense A/S) dedicated software. Mean experimental $\mathrm{N}_{2} \mathrm{O}$ concentration was calculated from triplicates of three individual experiments. The final mean was corrected for the background signal detected in pure LB.

\section{STATISTICAL ANALYSIS}

Data was analyzed for statistical significance with Prism 4 software (GraphPad Software, Inc., La Jolla, CA, USA). Unless otherwise mentioned, parametric data was analyzed by One-Way ANOVA with Dunnett's multiple comparison test and non-parametric by Friedman's test with Dunn's multiple comparison. $P<0.05$ was considered significant.

\section{RESULTS}

\section{DENITRIFICATION HAS A SIGNIFICANT ROLE IN ANOXIC GROWTH OF} PA01 AND CLINICAL ISOLATES AT PHYSIOLOGICAL LEVELS OF N0-

The specific growth rates of $P$. aeruginosa grown for $20 \mathrm{~h}$ in anoxic LB supplemented with physiologically relevant concentrations of $\mathrm{NO}_{3}^{-}\left(0-1 \mathrm{mM}\right.$ of $\left.\mathrm{NO}_{3}^{-}\right)$were calculated. PAO1 (Figure 2A) and 12 clinical isolates (5 mucoid and 7 non-mucoid) (Figure 2B) displayed a significant increase in specific growth rate as compared to the unsupplemented control at $\geq 150 \mu \mathrm{M} \mathrm{NO}_{3}^{-}(p=$ $0.0138)$ and $\geq 100 \mu \mathrm{M}(p=0.0132) \mathrm{NO}_{3}^{-}$, respectively. Despite the considerable variation between the growth rates of the clinical isolates, there was no significant correlation with the duration of infection as well as no significant difference between the growth rates of the mucoid and non-mucoid clinical isolates.

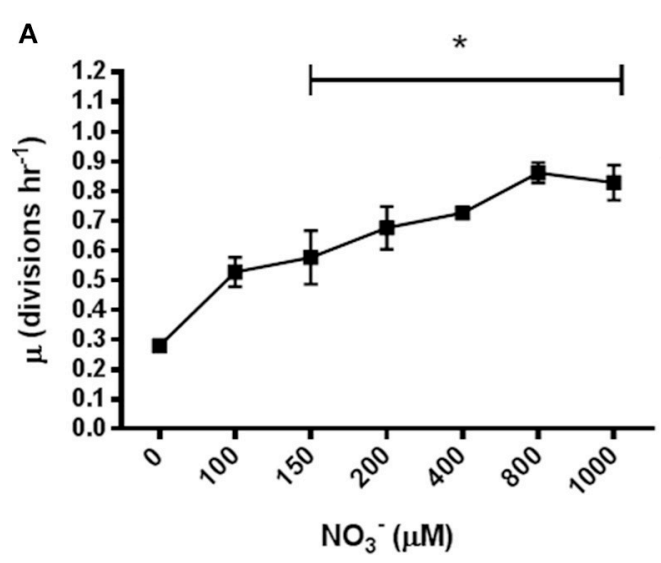

FIGURE 2 | Specific growth rates $(\mu)$ of $\boldsymbol{P}$ aeruginosa in anoxic LB supplemented with $\mathbf{N O}_{\mathbf{3}}^{-}$. (A) PAO1, mean \pm s.e.m. of triplicate experiments, (B) clinical isolates, $N=12,7$ non-mucoid strains

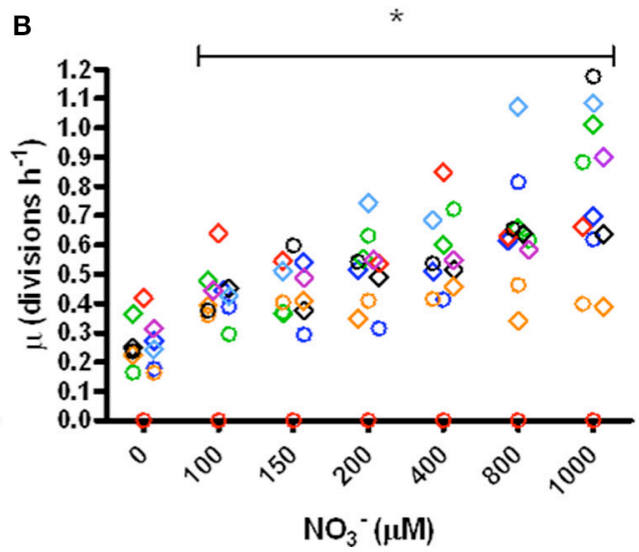

indicated by diamonds and 5 mucoid strains indicated by circles. Colors indicate the 7 patients isolated from $* p \leq 0.05$ significant change from $0 \mu \mathrm{M}$. 


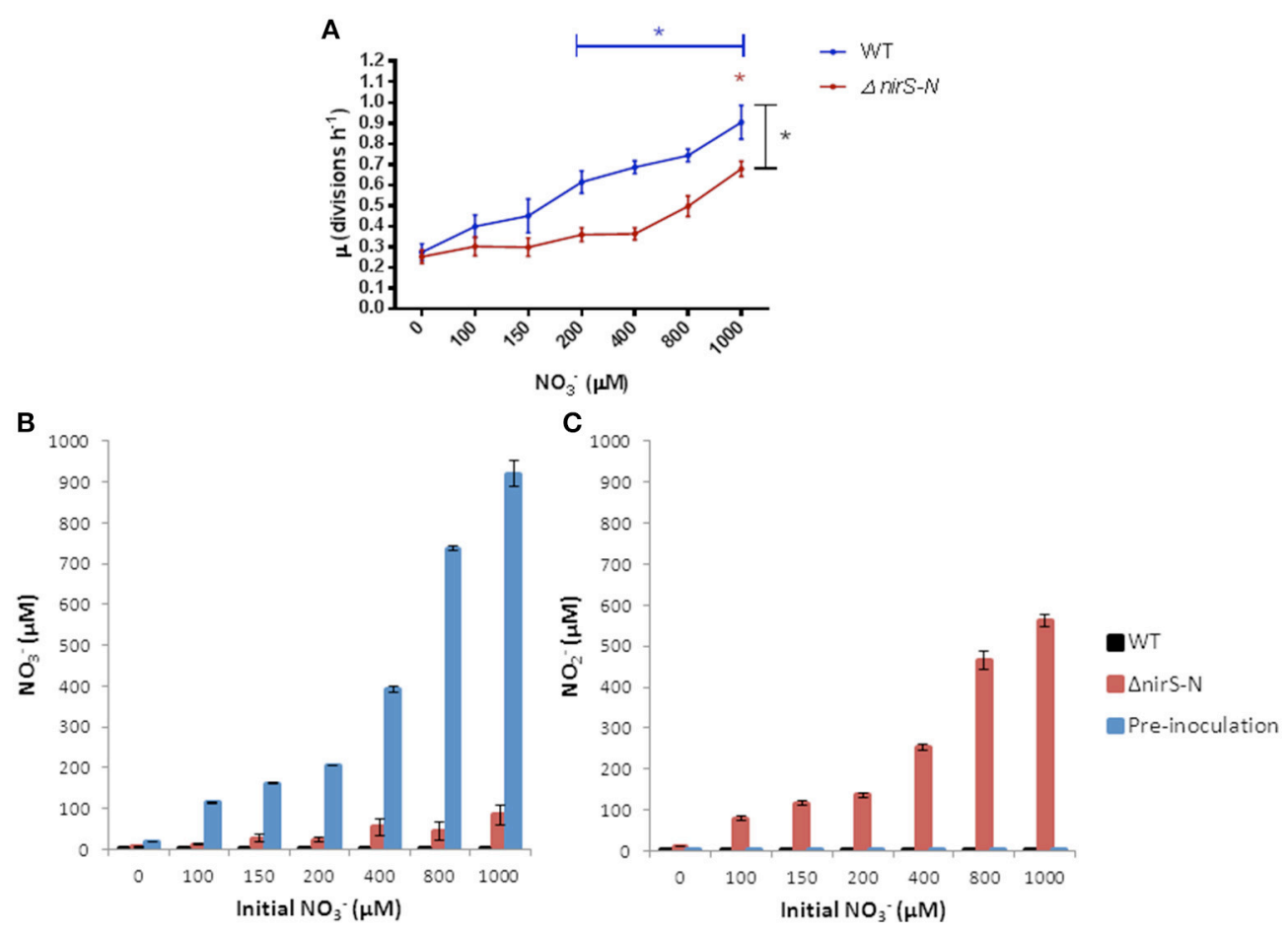

FIGURE 3 | (A) Specific growth rates $(\mu)$ of $P$. aeruginosa (WT and $\Delta$ nirS-N PAO1) grown in anoxic LB supplemented with $\mathrm{NO}_{3}^{-}$. Mean \pm s.e.m. of triplicate experiments, ${ }^{*} p \leq 0.05$ Blue and red * indicate significant increase in $\mu$ from $0 \mu \mathrm{M}$ calculated by
One-Way ANOVA. Black * indicate significant difference $(p=0.0316)$ between conditions $(\geq 400 \mu \mathrm{M})$ as calculated by Two-Way ANOVA. (B) $\mathrm{NO}_{3}^{-}$and (C) $\mathrm{NO}_{2}^{-}$content of anoxic sterile filtered growth media after $20 \mathrm{~h}$.
The suitability of the assay was demonstrated in a pilot study with anoxic cultures of PAO1 supplemented with $100 \mathrm{mM} \mathrm{NO}_{3}^{-}$, where our measured growth rate of 0.7 divisions $\mathrm{h}^{-1}$ and final $\mathrm{OD}_{600}$ of 1.0 (data not shown) corresponded well with previously reported growth rates of $P$. aeruginosa (Alvarez-Ortega and Harwood, 2007; Lee et al., 2012; Fang et al., 2013).

To discern the portion of growth attributable to denitrification, we compared the specific growth rates in anoxic cultures supplemented with $\mathrm{NO}_{3}^{-}$of the WT to a $\Delta$ nirS- $N$ mutant, which is able to reduce $\mathrm{NO}_{3}^{-}$to $\mathrm{NO}_{2}^{-}$, but whith a blocked first step of strict denitrification due to the inability to reduce $\mathrm{NO}_{2}^{-}$to $\mathrm{NO}$, under the same growth conditions were estimated (Figure 3A). $\mathrm{NO}_{3}^{-}$supports modest growth of the $\Delta$ nirS-N mutant with increasing $\mathrm{NO}_{3}^{-}$supplementation in accordance with Nar's contribution to proton motive force generation (Chen and Strous, 2013), but with a significant reduction in growth as compared to the $\mathrm{WT}$ at $\mathrm{NO}_{3}^{-} \geq 400 \mu \mathrm{M}(p=0.0316)$. One $\mathrm{mM} \mathrm{NO}_{3}^{-}$was required to initiate a significant increase in growth rate from the unsupplemented control in the $\Delta$ nirS- $N$ mutant $(p=0.0021)$.

The consumption of $\mathrm{NO}_{3}^{-}$and the accumulation of $\mathrm{NO}_{2}^{-}$in the sterile filtered growth media of the $\Delta$ nirS-N mutant at $20 \mathrm{~h}$ confirmed that the ability to reduce $\mathrm{NO}_{3}^{-}$to $\mathrm{NO}_{2}^{-}$was present in the $\Delta$ nirS-N mutant, but that the mutant failed to further reduce $\mathrm{NO}_{2}^{-}$as opposed to the total consumption of $\mathrm{NO}_{2}^{-}$by the WT. Furthemore, we demonstrated very low concentrations of $\mathrm{NO}_{3}^{-}$ and $\mathrm{NO}_{2}^{-}$pre-inoculation in $\mathrm{LB}$ and that the concentration of $\mathrm{NO}_{2}^{-}$was not affected by $\mathrm{NO}_{3}^{-}$(Figures 3B,C).

\section{DYNAMIC INCREASE IN DENITRIFICATION REDUCTASE PROMOTER ACTIVATION AT $400 \mu \mathrm{M} \mathbf{N O}_{3}^{-}$}

The reporter strains were grown under anoxia for $20 \mathrm{~h}$ supplemented with $400 \mu \mathrm{M} \mathrm{NO}_{3}^{-}$and the fluorescence measured post chloramphenicol addition with OFR by flow cytometry (Figure 4). The activity of all four promoters was significantly increased during supplementation with $400 \mu \mathrm{M} \mathrm{NO}_{3}$, but the time course varied. The Nar activity showed a small peak at $2 \mathrm{~h}$ $(p<0.0001)$ in comparison to Nor, which showed a stronger peak at $2-3 \mathrm{~h}(p<0.0001)$. Nir and Nos first showed significant upregulated promoter activity after $1 \mathrm{~h}$ and continued to be so over $20 \mathrm{~h}(p<0.0001$ and 0.0273$)$. In all reductases other than the Nos, there were also periods of significant upregulation in the unsupplemented control, but for shorter periods of time and with lower peaks. The transcripts of the denitrification reductase genes in PAO1 grown under anoxia with $400 \mu \mathrm{M} \mathrm{NO}_{3}^{-}$hours showed significant upregulation of nirS, nor $C$ and nosR after $3 \mathrm{~h}$ $(p$-values $=0.014,0.014$, and 0.04) (Figure 5).

We noted that anoxic conditions alone were apparently sufficient to trigger upregulation of some denitrification reductases as previously observed in other planktonic and biofilm studies (Härtig and Zumft, 1999; Hentzer et al., 2005; Schreiber et al., 2007) and that LB is a rich medium which we found to contain $\sim 20 \mu \mathrm{M} \mathrm{NO}_{3}^{-}$. We speculate that this is an explanation for the observed upregulation in our unsupplemented controls. However, the focus of the present study is on the differences due to the additional physiological levels of $\mathrm{NO}_{3}^{-}$supplementation. 

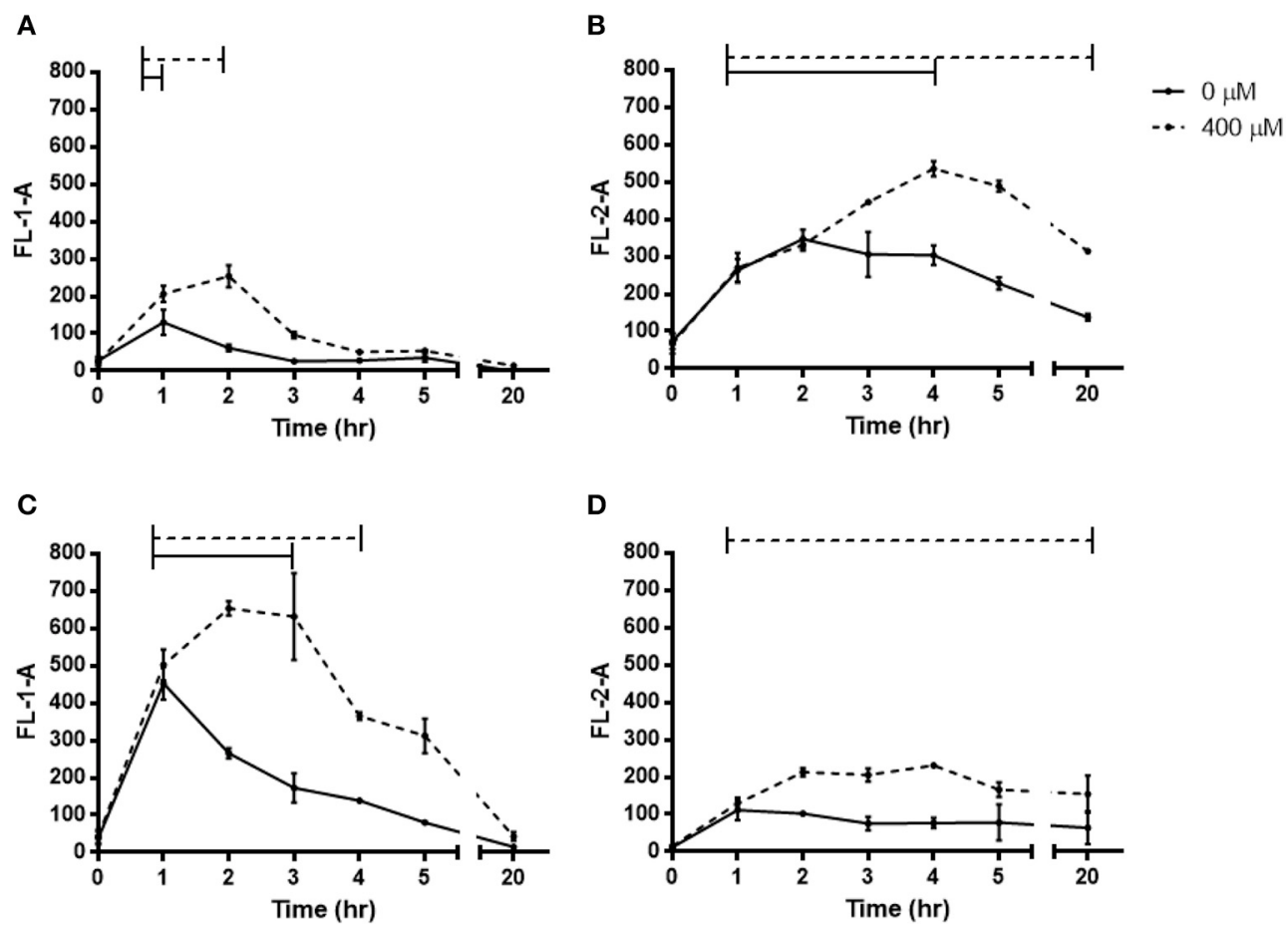

FIGURE 4 | Fluorescence of denitrification reporter promoters of $P$. aeruginosa PAO1 during anoxic growth with 0 or $400 \mu \mathrm{M} \mathrm{NO}_{3}^{-}$. (A) narK $_{1}$-eGFP, (B) nirS-dsredexpress, (C) norC-eGFP, (D) nosZ-dsredexpress.
Mean \pm s.e.m. as measured by flow cytometry from triplicates. eGFP was detected in FL-1-A, DsRed-Express was detected in FL-2-A. Bars above represent the period of time of significant increase $p \leq 0.05$.

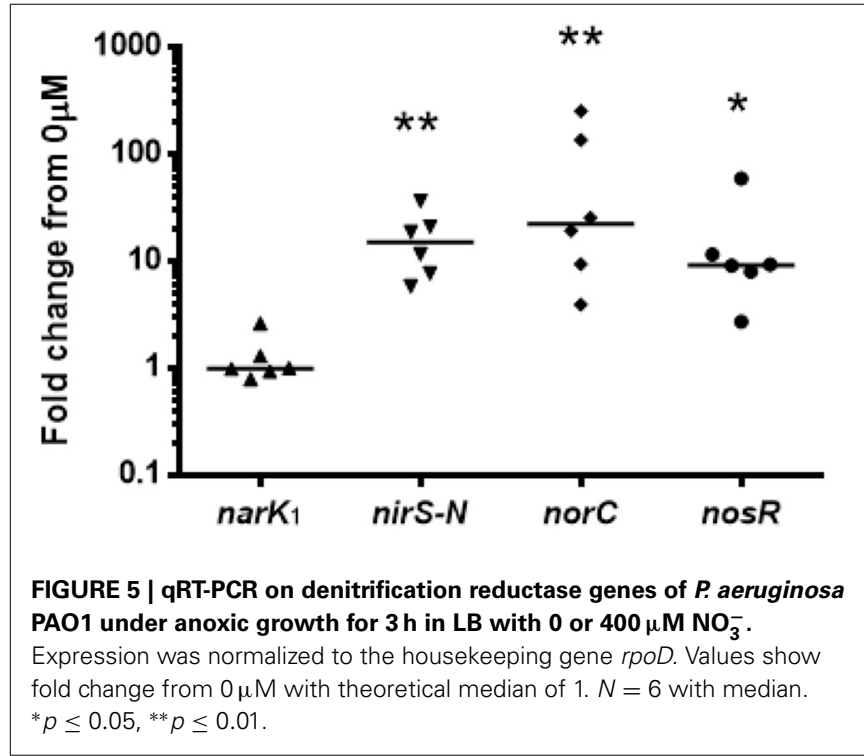

\section{$\mathrm{NO}_{3}^{-}$IS RAPIDLY CONSUMED WITH A SUBSEQUENT TRANSIENT INCREASE OF N0- IN ANOXIC GROWTH MEDIA}

Medium from the reporter PAO1 strains showed that $400 \mu \mathrm{M}$ $\mathrm{NO}_{3}^{-}$was depleted to below the detection level of the Griess assay within just $2 \mathrm{~h}$ with a transient increase in the product of its reduction, $\mathrm{NO}_{2}^{-}$(Figure 6). This rapid depletion combined with the time taken to harvest the supernatant is the likely

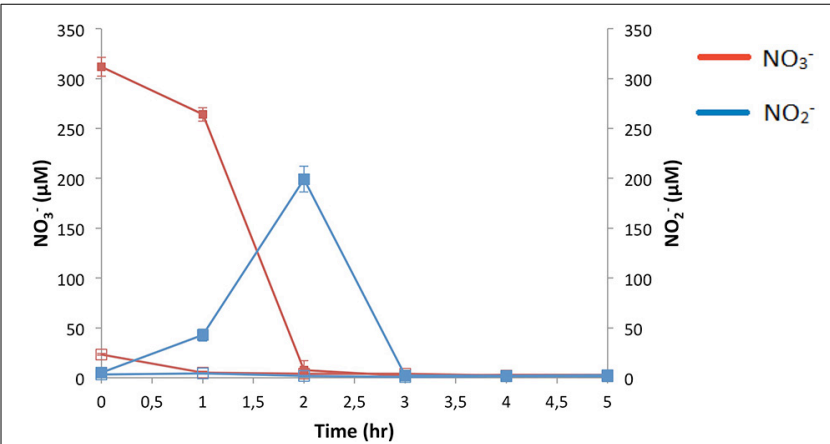

FIGURE 6 | Consumption and production of $\mathrm{NO}_{3}^{-}$and $\mathrm{NO}_{2}^{-}$during anaerobic growth of $\boldsymbol{P}$ aeruginosa PAO1. $N=4$, mean \pm s.e.m. Initial $\mathrm{NO}_{3}^{-}$: Open squares $0 \mu \mathrm{M} \mathrm{KNO}_{3}$, closed squares $400 \mu \mathrm{M} \mathrm{KNO}_{3}$.

explanation for the initial time point showing somewhat less than the expected $400 \mu \mathrm{M} \mathrm{NO}_{3}^{-}$, as the media pre-inoculation was tested and confirmed to contain $400 \mu \mathrm{M} \mathrm{NO}_{3}^{-}$.

\section{$\mathrm{N}_{2} \mathrm{O}$ IS PRODUCED IN RESPONSE TO $\mathrm{NO}_{3}^{-}$SUPPLEMENTATION}

The $\triangle$ nos $Z$ mutant and a WT PAO1 strain were grown with physiological concentrations of $\mathrm{NO}_{3}^{-}$under anoxia and the average $\mathrm{N}_{2} \mathrm{O}$ accumulation over $20 \mathrm{~h}$ detected. With as little as $62.5 \mu \mathrm{M} \mathrm{NO} \mathrm{N}_{3}^{-}$, a significant production of $\mathrm{N}_{2} \mathrm{O}$ was stimulated $(p=0.0125)$ (Figure 7). The WT produced $<10 \mu \mathrm{M}$ of $\mathrm{N}_{2} \mathrm{O}$ at all experimental concentrations of $\mathrm{NO}_{3}^{-}$; confirming 


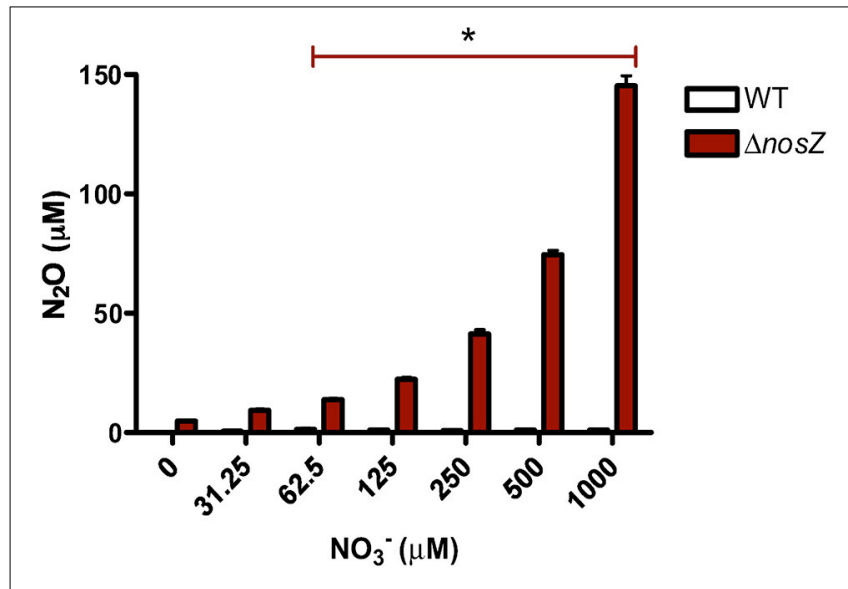

FIGURE $7 \mid \mathrm{N}_{2} \mathrm{O}$ production by $P$. aeruginosa PAO1 grown over $20 \mathrm{~h}$ in anoxic LB supplemented with $\mathrm{NO}_{3}^{-}$in triplicate. Mean \pm s.e.m. ${ }^{*} p \leq 0.05$ indicating significant increase of $\mathrm{N}_{2} \mathrm{O}$ production by $\Delta$ nos $Z$.

the defective conversion of $\mathrm{N}_{2} \mathrm{O}$ to $\mathrm{N}_{2}$ by the $\Delta \operatorname{nos} Z$ mutant.

\section{DISCUSSION}

$P$. aeruginosa is able to thrive under anoxic conditions by performing denitrification. Our initial studies performed with clinical isolates and PAO1 under anoxic conditions showed that physiological concentrations of $\mathrm{NO}_{3}^{-}$are sufficient to support a significant increase in growth rate, even in cultures supplemented with less $\mathrm{NO}_{3}^{-}$than the $400 \mu \mathrm{M}$ applied by Palmer et al. (2007).

The anoxic growth rates obtained are comparable to those reported in CF lungs and sputum, except for the very low growth rates in some of the clinical samples from CF lungs and sputum (Yang et al., 2008; Kragh et al., 2014). This is likely due to our planktonic studies representing a slightly faster growth rate as the shaken cells have equal access to nutrients in the media, whereas in the biofilm mode of growth in the lungs, internal cells are assumed to have access to less nutrients, including $\mathrm{NO}_{3}^{-}$, due to diffusion limitation and utilization by cells at the periphery of the biofilm (Bjarnsholt et al., 2009). Additionally, $\sim 10 \%$ of the cells in clinical samples appear to be in stationary phase (Yang et al., 2008) whereas the growth rates in our experiments are calculated from the exponential growth phase. In the lungs, $P$. aeruginosa is also under continual attack from the host inflammatory response and antibiotic stress (Høiby, 2006), which is also likely to reduce the rate of growth.

Nar is required for anoxic growth at physiological levels of $\mathrm{NO}_{3}^{-}$in CF sputum (Palmer et al., 2007) and accordingly $\mathrm{NO}_{3}^{-}$ reduction alone is able to generate some growth as seen in the $\Delta$ nirS- $N$ mutant, unable to perform the subsequent $\mathrm{NO}_{2}^{-}$ reduction and therefore blocking denitrification. However, we demonstrate that the $\Delta$ nirS-N mutant requires the highest physiological concentration of $1 \mathrm{mM} \mathrm{NO}_{3}^{-}$, seen only in exacerbated CF patients following antimicrobial treatment (Grasemann et al., 1998), to enable a significant increase in growth rate as well as a significant reduction of growth as compared to the WT. This indicates a substantial additional contribution of denitrification to the observed anoxic growth of $P$. aeruginosa at physiological levels of $\mathrm{NO}_{3}^{-}$. Anoxic growth of mutants with defective Nir was also reduced at concentrations of $\mathrm{NO}_{3}^{-}$greater than physiological levels [10 mM (Schreiber et al., 2007) and $100 \mathrm{mM}$ (Filiatrault et al., 2006)].

In addition to supporting anoxic growth, Nir may promote the persistence of $P$. aeruginosa in the infected CF lungs as Nir is required for type III secretion resulting in prolonged survival in human monocytes (Van Alst et al., 2009) and enhanced virulence (Filiatrault et al., 2006). This supports the idea that denitrification is necessary for achieving the observed growth of $P$. aeruginosa in the lungs.

The dynamic increase in the promoter activity of all four denitrification reductases over $20 \mathrm{~h}$ and increased expression of all transcripts but the $n a r K_{1}$ at $3 \mathrm{~h}$ with $400 \mu \mathrm{M} \mathrm{NO}_{3}^{-}$further emphasized the engagement of denitrification. The explanation for the transient peak in Nar expression and lack of upregulation at $3 \mathrm{~h}$ became apparent after analysing the growth media for $\mathrm{NO}_{3}^{-}$content, showing depletion after just $2 \mathrm{~h}$. Expression of Nar is controlled in part by the two-component $\mathrm{NO}_{3}^{-}$-sensing regulator NarX-L (Schreiber et al., 2007; Schobert and Jahn, 2010) so presumably after $\mathrm{NO}_{3}^{-}$depletion Nar expression is no longer induced. The Nor is also proposed to be under NarX-L control (Schobert and Jahn, 2010), which would explain the decrease in promoter activity after $2 \mathrm{~h}$.

The Nar product, $\mathrm{NO}_{2}^{-}$displayed a transient increase in the growth media which was similarly rapidly depleted by $3 \mathrm{~h}$. However, the expression of Nir and Nos appeared to be less tightly regulated by $\mathrm{N}$-oxide concentration as they were still significantly upregulated at $20 \mathrm{~h}$, and in the case of the Nir, only a modest increase in expression was stimulated by $\mathrm{NO}_{3}^{-}$ supplementation. The additional $\mathrm{O}_{2}$-sensing Anr regulator and downstream NO sensing dissimilative nitrate respiration (Dnr) regulator (Schreiber et al., 2007; Schobert and Jahn, 2010; Trunk et al., 2010; Arai, 2011) may play a more important role in Nir and Nos regulation (Schreiber et al., 2007; Schobert and Jahn, 2010) and hence their expression more responsive to the anoxic conditions and the downstream denitrification product NO resulting in prolonged increase in expression.

As $\mathrm{N}$-oxides are not exclusively utilized in strict denitrification $-\mathrm{NO}_{3}^{-}$reduction is also able to feed into dissimilatory pathways for ammonia excretion or into assimilatory pathways for incorporation into biomolecules (Zumft, 1997) — we also studied $\mathrm{N}_{2} \mathrm{O}$ production. The known pathways for $\mathrm{N}_{2} \mathrm{O}$ production are denitrification and nitrification via oxidation of hydroxylamine to $\mathrm{N}_{2} \mathrm{O}$ (Khalila et al., 2004). As of yet, there is no evidence to suggest that $P$. aeruginosa performs or possesses homologs of the enzymes required for nitrification [PAO1 Genome Sequence, Pseudomonas Genome Database (Winsor et al., 2011)]. Additionally, the process requires $\mathrm{O}_{2}$ (Meyer et al., 2008) and thus for our anoxic experiments we assumed that all detected $\mathrm{N}_{2} \mathrm{O}$ was produced via the denitrification pathway and therefore acted as a specific marker. In the $P$. aeruginosa nitrous oxide reductase mutant $\Delta$ nos $Z$, unableto reduce $\mathrm{N}_{2} \mathrm{O}$ to $\mathrm{N}_{2}$, we found a significant accumulation of $\mathrm{N}_{2} \mathrm{O}$ in the anoxic growth media with as little $\mathrm{NO}_{3}^{-}$supplementation as $62.5 \mu \mathrm{M}$. This finding further supports that $P$. aeruginosa employs denitrification to 
obtain energy for growth at physiological levels of $\mathrm{NO}_{3}^{-}$in anoxic conditions.

Interestingly, one late clinical strain isolated from a patient chronically infected for 35 years, was unable to grow in anoxic conditions with $\mathrm{NO}_{3}^{-}$. This may relate to adaptations of more flexible nitrate metabolism over time, with denitrification suggested to no longer be essential for growth for some strains at later phases of infection (Oberhardt et al., 2010; Cramer et al., 2011). While $\mathrm{NO}_{3}^{-}$was unable to stimulate anoxic growth of the late isolate, alternative anoxic growth may occur by arginine fermentation (Vander Wauven et al., 1984) and survival could be facilitated by pyruvate fermentation (Eschbach et al., 2004) and phenazine redox cycling (Glasser et al., 2014; Quinn et al., 2014). Alternatively, the late isolate may have adapted to favor growth in the alveoles where oxygen is supplied by inspired air and capillaries surrounding the alveoles (West, 2000).

It has previously been shown that micro-oxic conditions are able to support growth of $P$. aeruginosa (Alvarez-Ortega and Harwood, 2007). Here we substantiate that physiological concentrations of $\mathrm{NO}_{3}^{-}$are also able to support growth by denitrification in anoxic conditions, highlighting the flexibility of $P$. aeruginosa's ability to survive in a range of environments in the CF airways (Worlitzsch et al., 2002; Aanaes et al., 2011; Kolpen et al., 2014a). Interestingly, physiological concentrations of $\mathrm{NO}_{3}^{-}$may also enhance growth of $P$. aeruginosa even at micro-oxic conditions since a growth advantage of laboratory strains carrying a las $R$ mutation, which is associated with severe lung damage in infected CF patients (Hoffman et al., 2009), was obtained with supplementation of only $125 \mu \mathrm{M} \mathrm{NO}_{3}^{-}$ in conditions with limited $\mathrm{O}_{2}$ mass-transfer (Hoffman et al., 2010).

In conclusion, $P$. aeruginosa is readily able to adapt to the physiological levels of $\mathrm{NO}_{3}^{-}$and lack of $\mathrm{O}_{2}$ in the infected CF lungs by employing denitrification. The ability of $P$. aeruginosa to grow under anoxia has clinical relevance as multiple classes of antibiotics are known to have reduced efficacy in the absence of $\mathrm{O}_{2}$ (Walters et al., 2003; Dwyer et al., 2014). Denitrification may consequently be a major factor in $P$. aeruginosa's observed tolerance to antibiotic treatment in CF patients (Høiby et al., 2010). This tolerance may be overcome by directing antibacterial treatment against denitrification as suggested by the downregulation of nar $G$ and nar $H$ resulting in increased susceptibility of $P$. aeruginosa to fosfomycin and tobramycin combination treatment under anoxic conditions (McCaughey et al., 2013). Denitrification has also recently been proposed to contribute to the pathogenicity of bacterial species infecting CF lungs due to its activity in P. aeruginosa as well as the highly pathogenic species Achromobacter xylosoxidans and Burkholderia multivorans in comparison to the less pathogenic Stenotrophomonas maltophilia which is unable to perform denitrification (Kolpen et al., 2014c). Accordingly, our results underline the importance of developing novel treatments that target $P$. aeruginosa's flexible metabolism more broadly, with the denitrification reductases presenting potential targets, and that can be administered to reach the varied lung microenvironments that $P$. aeruginosa is able to adapt to and persist within.

\section{ACKNOWLEDGMENTS}

With many thanks to The British Council Erasmus Work Placement programme for making this study possible, to the Danish Cystic Fibrosis Association and to Anne Kirstine Nielsen for technical assistance.

\section{REFERENCES}

Aanaes, K., Rickelt, L. F., Johansen, H. K., von Buchwald, C., Pressler, T., Høiby, N., et al. (2011). Decreased mucosal oxygen tension in the maxillary sinuses in patients with cystic fibrosis. J. Cyst. Fibros. 10, 114-201. doi: 10.1016/j.jcf.2010.12.002

Alvarez-Ortega, C., and Harwood, C. S. (2007). Responses of Pseudomonas aeruginosa to low oxygen indicate that growth in the cystic fibrosis lung is by aerobic respiration. Mol. Microbiol. 65, 153-165. doi: 10.1111/j.1365-2958.2007.05772.x

Andersen, K., Kjaer, T., and Revsbech, N. P. (2001). An oxygen insentitive microsensor for nitrous oxide. Sensor. Actuat. B Chem. 81, 42-48. doi: 10.1016/S09254005(01)00924-8

Arai, H. (2011). Regulation and function of versatile aerobic and anaerobic respiratory metabolism in Psuedomonas aeruginosa. Front. Microbiol. 2:103. doi: 10.3389/fmicb.2011.00103

Beckmann, C., Brittnacher, M., Ernst, R., Mayer-Hamblett, N., Miller, S. I., and Burns, J. L. (2005). Use of phage display to identify potential Pseudomonas aeruginosa gene products relevant to early cystic fibrosis airway infections. Infect. Immun. 73, 444-452. doi: 10.1128/IAI.73.1.444-452.2005

Bjarnsholt, T., Jensen, P. Ø., Fiandaca, M. J., Pedersen, J., Hansen, C. R., Andersen, C. B., et al. (2009). Pseudomonas aeruginosa biofilms in the respiratory tract of cystic fibrosis patients. Pediatr. Pulmonol. 44, 547-558. doi: 10.1002/ppul.21011

Chen, J., and Strous, M. (2013). Denitrification and aerobic respiration, hybrid electron transport chain and co-evolution. Biochem. Biophys. Acta 1827, 136-144. doi: 10.1016/j.bbabio.2012.10.002

Choi, K. H., Kumar, A., and Schweizer, H. P. (2005). A 10-min method for preparation of highly electrocompetent Pseudomonas aeruginosa cells: application for DNA fragment transfer between chromosomes and plasmid transformation. J. Microbiol. Met. 64, 391-397. doi: 10.1016/j.mimet.2005.06.001

Craggs, T. D. (2009). Green fluorescent protein: structure, folding and chromophore maturation. Chem. Soc. Rev. 38, 2865-2875. doi: 10.1039/b903641p

Cramer, N., Klockgether, J., Wrasman, K., Schmidt, M., Davenport, C. F., and Tümmler, B. (2011). Microevolution of the major common Pseudomonas aeruginosa clones C and PA14 in cystic fibrosis lungs. Environ. Microbiol. 13, 1690-1704. doi: 10.1111/j.1462-2920.2011.02483.x

Dwyer, D. J., Belenky, P. A., Yang, J. H., MacDonald, I. C., Martell, J. D., Takahashi, N., et al. (2014). Antibiotics induce redox-related physiological alterations as part of their lethality. Proc. Natl. Acad. Sci. U.S.A. 111, E2100-E2109. doi: 10.1073/pnas.1401876111

Eschbach, M., Schreiber, K., Trunk, K., Buer, J., Jahn, D., and Schobert, M. (2004). Long-term anaerobic survival of the opportunistic pathogen Pseudomonas aeruginosa via pyruvate fermentation. J. Bacteriol. 186, 4596-4604. doi: 10.1128/JB.186.14.4596-4604.2004

Fang, H., Toyofuku, M., Kiyokawa, T., Ichihashi, A., Tateda, K., and Nomura, N. (2013). The impact of anaerobiosis on strain-dependent phenotypic variations in Pseudomonas aeruginosa. Biosci. Biotechnol. Biochem. 77, 1747-1752. doi: 10.1271/bbb.130309

Filiatrault, M. J., Picardo, K. F., Ngai, H., Passador, L., and Iglewski, B. H. (2006). Identification of Pseudomonas aeruginosa genes involved in virulence and anaerobic growth. Infect. Immun. 74, 4237-4245. doi: 10.1128/IAI. 02014-05

Gayon, U., and Dupetit, G. (1886). Recherches sur la reduction des nitrates par les infinement petits. Mem. Soc. Sci. Phys. Nat. Bordeaux. Ser. 3, 201-307.

Glasser, N. R., Kern, S. E., and Newman, D. K. (2014). Phenazine redox cycling enhances anaerobic survival in Pseudomonas aeruginosa by facilitating generation of ATP and a proton-motive force. Mol. Microbiol. 92, 399-412. doi: 10.1111/mmi.12566

Grasemann, H., Ioannidis, I., Tomkiewicz, R. P., de Groot, H., Rubin, B., and Ratjen, F. (1998). Nitric oxide metabolites in cystic fibrosis lung disease. Arch. Dis. Child 78, 49-53. doi: 10.1136/adc.78.1.49

Härtig, E., and Zumft, W. G. (1999). Kinetics of nirS expression (cytochrome $c d_{1}$ nitrite reductase) in Pseudomonas stutzeri during the transition from aerobic 
respiration to denitrification: evidence for a denitrification-specific nitrate- and nitrite-responsive regulatory system. J Bacteriol. 181, 161-166.

Hentzer, M., Eberl, L., and Givskov, M. (2005). Transcriptome analysis of Pseudomonas aeruginosa biofilm development: anaerobic respiration and iron limitation. Biofilms 2, 37-61. doi: 10.1017/S1479050505001699

Hoboth, C., Hoffmann, R., Eichner, A., Henke, C., Schmoldt, S., Imhof, A., et al. (2009). Dynamics of adaptive microevolution of hypermutable Pseudomonas aeruginosa during chronic pulmonary infection in patients with cystic fibrosis. J. Infect. Dis. 200, 118-130. doi: 10.1086/599360

Hoffman, L. R., Kulasekara, H. D., Emerson, J., Houston, L. S., Burns, J. L., Ramsey, B. W., et al. (2009). Pseudomonas aeruginosa lasR mutants are associated with cystic fibrosis lung disease progression. J. Cyst. Fibros 8, 66-70. doi: 10.1016/j.jcf.2008.09.006

Hoffman, L. R., Richardson, A. R., Houston, L. S., Kulasekara, H. D., MartensHabbena, W., Klausen, M., et al. (2010). Nutrient availability as a mechanism for selection of antibiotic tolerant Pseudomonas aeruginosa within the CF airway. PLoS Pathog. 6:e1000712. doi: 10.1371/journal.ppat.1000712

Høiby, N. (2006). P. aeruginosa in cystic fibrosis patients resists host defenses, antibiotics. Microbe 1, 571-577.

Høiby, N., Bjarnsholt, T., Givskov, M., Molin, S., and Ciofu, O. (2010). Antibiotic resistance of bacterial biofilms. Int. J. Antimicrob. Agents 35, 322-332. doi: 10.1016/j.ijantimicag.2009.12.011

Holloway, B. W., Krishnapillai, V., and Morgan, A. F. (1979). Chromosomal genetics of Pseudomonas. Microbiol. Rev. 43, 73-102.

Khalila, K., Mary, B., and Renault, P. (2004). Nitrous oxide production by nitrification and denitrification in soil aggregates as affected by $\mathrm{O}_{2}$ concentration. Soil Biol. Biochem. 36, 687-699. doi: 10.1016/j.soilbio.2004.01.004

Koch, C., and Høiby, N. (2000). Diagnosis and treatment of cystic fibrosis. Respiration 67, 239-247. doi: 10.1159/000029503

Kolpen, M., Bjarnsholt, T., Moser, C., Hansen, C. R., Richelt, L., Kühl, M., et al. (2014a). Nitric oxide production by polymorphonuclear leukocytes in infected cystic fibrosis sputum. Clin. Exp. Immunol. 177, 310-319. doi: 10.1111/cei.12318

Kolpen, M., Kühl, M., Bjarnsholt, T., Moser, C., Hansen, C. R., Liengaard, L., et al. (2014b). Nitrous oxide production in sputum from cystic fibrosis patients with chronic Pseudomonas aeruginosa lung infection. PLoS ONE 9:e84353. doi: 10.1371/journal.pone.0084353

Kolpen, M., Kragh, K. N., Bjarnsholt, T., Line, L., Hansen, C. R., Dalbøge, C. S., et al. (2014c). Denitrification by cystic fibrosis pathogens stenotrophomonas maltophilia is dormant in sputum. Int. J. Med. Microbiol. doi: 10.1016/j.ijmm.2014.07.002. [Epub ahead of print].

Kolpen, M., Hansen, C. R., Bjarnsholt, T., Moser, C., Christensen, L. D., Gennip, M. V., et al. (2010). Polymorphonuclear leucocytes consume oxygen in sputum from chronic Pseudomonas aeruginosa pneumonia in cystic fibrosis. Thorax 65 , 57-62. doi: 10.1136/thx.2009.114512

Kragh, K. N., Alhede, M., Jensen, P. Ø., Moser, C., Scheike, T., Jacobsen, C. S. et al. (2014). Polymorphonuclear leukocytes restrict the growth of Pseudomonas aeruginosa in the lungs of cystic fibrosis patients. Infect. Immun. 82, 4477-4486. doi: 10.1128/IAI.01969-14

Lee, B., Schjerling, C. K., Kirkby, N., Hoffmann, N., Borup, R., Molin, S., et al. (2011). Mucoid $P$. aeruginosa isolates maintain the biofilm formation capacity and the gene expression profiles during the chronic lung infection of $\mathrm{CF}$ patients. APMIS 119, 263-274. doi: 10.1111/j.1600-0463.2011.02726.x

Lee, K. M., Go, J., Yoon, M. Y., Park, Y., Kim, S. C., Yong, D. E., et al. (2012). Vitamin B12-ediated restoration of defective anaerobic growth leads to reduced biofilm formation in Pseudomonas aeruginosa. Infect. Immun. 80, 1639-1649. doi: 10.1128/IAI.06161-11

Maseda, H., Sawada, I., Saito, K., Uchiyama, H., Nakae, T., and Nomura, N. (2004). Enhancement of the mexAB-oprM efflux pump expression by a quorum-sensing autoinducer and its cancellation by a regulator, MexT, of the mexEF-oprN efflux pump operon in Pseudomonas aeruginosa. Antimicrob. Agents Chemother. 48, 1320-1328. doi: 10.1128/AAC.48.4.1320-1328.2004

McCaughey, G., Gilpin, D. F., Schneiders, T., Hoffman, L. R., McKevitt, M., Elborn, J. S., et al. (2013). Fosfomycin and tobramycin in combination downregulate nitrate eductase genes $\mathrm{NarG}$ and narH, resulting in increased activity against Pseudomonas aeruginosa under anaerobic conditions. Antimicrob. Agents. Chemother. 57, 5406-5414. doi: 10.1128/AAC.00750-13

Meyer, R. L., Allen, D. E., and Schmidt, S. (2008). Nitrification and denitrification as sources of sediment nitrous oxide production: a microsensor approach. Mar. Chem. 110, 68-76. doi: 10.1016/j.marchem.2008.02.004
Oberhardt, M. A., Goldberg, J. B., Hogardt, M., and Papin, J. A. (2010). Metabolic network analysis of Pseudomonas aeruginosa during chronic cystic fibrosis lung infection. J. Bacteriol. 192, 5534-5548. doi: 10.1128/JB.00900-10

Palmer, K. L., Brown, S. A., and Whiteley, M. (2007). Membrane-bound nitrate reductase is required for anaerobic growth in cystic fibrosis sputum. J. Bacteriol. 189, 4449-4455 doi: 10.1128/JB.00162-07

Quinn, R. A., Lim, Y. W., Maughan, H., Conrad, D., Rohwer, F., and Whiteson, K. L. (2014). Biogeochemical forces shape the composition and physiology of polymicrobial communities in the cystic fibrosis lung. mBio 5, e00956-e00913. doi: 10.1128/mBio.00956-13

Savli, H., Karadenizili, A., Kolayli, F., Gundes, S., Ozbeck, U., and Vahaboglu, H. (2003). Expression stability of six housekeeping genes: a proposal for resistance gene quantification studies of Pseudomonas aeruginosa by realtime quantitative RT-PCR. J. Med. Microbiol. 52, 403-408. doi: 10.1099/jmm. $0.05132-0$

Schobert, M., and Jahn, D. (2010). Anaerobic physiology of Pseudomonas aeruginosa in the cystic fibrosis lung. Int. J. Med. Microbiol. 300, 549-556. doi: 10.1016/j.ijmm.2010.08.007

Schreiber, K., Krieger, R., Benkert, B., Eschbach, M., Arai, H., Schobert, M., et al. (2007). The anaerobic regulatory network required for Pseudomonas aeruginosa nitrate respiration. J. Bacteriol. 189, 4310-4314. doi: 10.1128/JB.00240-07

Simon, R., O'Connell, M., Labes, M., and Pühler, A. (1986). Plasmid vector for the genetic analysis and manipulation of rhizobia and other gram-negative bacteria Methods Enzymol. 118, 640-659.

Son, M. S., Matthews, W. J. Jr., Kang, Y., Nguyen, D. T., and Hoang, T. T. (2007) In vivo evidence of Pseudomonas aeruginosa nutrient acquisition and pathogenesis in the lungs of cystic fibrosis patients. Infect. Immun. 75, 5313-5324. doi: 10.1128/IAI.01807-06

Strack, R. L., Strongin, D. E., Mets, L., Glick, B. S., and Keenan, R. J. (2010). Chromophore Formation in DsRed Occurs by a Branched Pathway. J. Am. Chem. Soc. 132, 8496-8505. doi: 10.1021/ja1030084

Toyofuku, M., Nomura, M., Fujii, T., Takaya, N., Maseda, H., Sawada, I., et al. (2007). Quorum sensing regulates denitrification in Pseudomonas aeruginosa PAO1. J. Bacteriol. 189, 4969-4972. doi: 10.1128/JB.00289-07

Toyofuku, M., Zhou, S., Sawada, I., Takaya, N., Uchimyama, H., and Nomura, N. (2013). Membrane vesicle formation is associated with pyocin production under denitrifying conditions in Pseudomonas aeruginosa PAO1. Environ. Microbiol. 16, 2927-2938. doi: 10.1111/1462-2920.12260

Trunk, K., Benkert, B., Quäck, N., Münch, R., Scheer, M., Garbe, J., et al. (2010). Anaerobic adaptation in Pseudomonas aeruginosa: definition of the Anr and Dnr regulons. Environ. Microbiol. 12, 1719-1733. doi: 10.1111/j.14622920.2010.02252.x

Tunney, M. M., Field, T. R., Moriarty, T. F., Patrick, S., Döring, G., Muhlebach, M. S., et al. (2008). Detection of anaerobic bacteria in high numbers in sputum from patients with cystic fibrosis. Am. J. Resp. Crit. Care Med. 177, 995-1001. doi: 10.1164/rccm.200708-1151OC

Van Alst, N. E., Wellington, M., Clark, V. L., Haidaris, C. G., and Iglewski, B. H. (2009). Nitrite reductase NirS is required for Type III secretion system expression and virulence in the human monocyte cell line THP-1 by Pseudomonas aeruginosa. Infect. Immun. 77, 4446-4454. doi: 10.1128/IAI.00822-09

Vander Wauven, C., Pierard, A., Kley-Raymann, M., and Haas, D. (1984). Pseudomonas aeruginosa mutants affected in anaerobic growth on arginine: evidence for a four-gene cluster encoding the arginine deiminase pathway. J. Bacteriol. 160, 928-934.

Walters, M. C., Roe, F., Bugnicourt, A., Franklin, M. J., and Stewart, P. S. (2003). Contributions of antibiotic penetration, oxygen limitation, and low metabolic activity to tolerance of Pseudomonas aeruginosa biofilms to ciprofloxacin and tobramycin. Antimicrob. Agents Chemother. 47, 317-323. doi: 10.1128/AAC.47. $1.317-323.2003$

West, J. B. (2000). Respiratory Physiology: The Essentials, 6th Edn. Baltimore, MD: Lippincott Williams \& Wilkins.

Widdel, F. (2007). Theory and Measurement of Bacterial Growth. Bremen: University Bremen.

Winsor, G. L., Lam, D. K., Fleming, L., Lo, R., Whiteside, M. D., Yu, N. Y., et al. (2011). Pseudomonas genome database: improved comparative analysis and population genomics capability for Pseudomonas genomes. Nucleic Acids Res. 39, D596-D600. doi: 10.1093/nar/gkq869

Worlitzsch, D., Tarran, R., Ulrich, M., Schwab, U., Cekici, A., Meyer, K. C., et al. (2002). Effects of reduced mucus oxygen concentration in airway 
Pseudomonas infections of cystic fibrosis patients. J. Clin. Invest. 109, 317-325. doi: 10.1172/JCI0213870

Yang, L., Haagensen, J. A. J., Jelsbak, L., Johansen, H. K., Sternberg, C., Høiby, N., et al. (2008). In situ growth rates and biofilm development of Pseudomonas aeruginosa populations in chronic lung infections. J. Bacteriol. 190, 2767-2776. doi: 10.1128/JB.01581-07

Yoon, S. S., Hennigan, R. F., Hilliard, G. M., Ochsner, U. A., Parvatiyar, K., Kamani, M. C., et al. (2002). Pseudomonas aeruginosa anaerobic respiration in biofilms: relationships to cystic fibrosis pathogenesis. Dev. Cell 3, 593-603. doi: 10.1016/S1534-5807(02) 00295-2

Zhang, C., Xing, X. H., and Lou, K. (2005). Rapid detection of a gfp-marked Enterobacter aerogenes under anaerobic conditions by aerobic fluorescence recovery. FEMS Microbiol. Lett. 249, 211-218. doi: 10.1016/j.femsle.2005. 05.051

Zumft, W. G. (1997). Cell biology and molecular basis of denitrification. Microbiol. Mol. Biol. Rev. 61, 533-616.

Zumft, W. G. (2005). Nitric oxide reductases of prokaryotes with emphasis on the respiratory, heme-copper oxidase type. J. Inorg. Biochem. 99, 194-215. doi: 10.1016/j.jinorgbio.2004.09.024
Conflict of Interest Statement: The authors declare that the research was conducted in the absence of any commercial or financial relationships that could be construed as a potential conflict of interest.

Received: 14 August 2014; accepted: 03 October 2014; published online: 24 October 2014.

Citation: Line L, Alhede M, Kolpen M, Kühl M, Ciofu O, Bjarnsholt T, Moser C, Toyofuku M, Nomura N, Høiby N and Jensen PØ (2014) Physiological levels of nitrate support anoxic growth by denitrification of Pseudomonas aeruginosa at growth rates reported in cystic fibrosis lungs and sputum. Front. Microbiol. 5:554. doi: 10.3389/ fmicb.2014.00554

This article was submitted to Infectious Diseases, a section of the journal Frontiers in Microbiology.

Copyright $\odot 2014$ Line, Alhede, Kolpen, Kühl, Ciofu, Bjarnsholt, Moser, Toyofuku, Nomura, Høiby and Jensen. This is an open-access article distributed under the terms of the Creative Commons Attribution License (CC BY). The use, distribution or reproduction in other forums is permitted, provided the original author(s) or licensor are credited and that the original publication in this journal is cited, in accordance with accepted academic practice. No use, distribution or reproduction is permitted which does not comply with these terms. 